SHORT REPORT

\title{
Intramedullary tuberculoma mimicking primary CNS lymphoma
}

\section{A A Mohit, P Santiago, R Rostomily}

J Neurol Neurosurg Psychiatry 2004;75:1636-1638. doi: 10.1136/jnnp.2003.029926

The incidence of primary central nervous system lymphoma (PCNSL) has been on the rise in the setting of immunodeficiency syndromes such as acquired immune deficiency syndrome (AIDS). Its diagnosis has been facilitated by the advent of a cerebrospinal fluid (CSF) Epstein-Barr virus (EBV) PCR assay. The reported high sensitivity and specificity of this assay has made it the cornerstone of diagnosis of PCNSL, replacing more traditional methods such as an open CNS biopsy. Here, we have described a patient with a known history of C3 AIDS presenting with lower extremity weakness and eventual myelopathy who was later diagnosed as having intramedullary PCNSL after detection of EBV DNA in his CSF. After failing to respond to radiotherapy, he underwent a spinal cord biopsy revealing intramedullary tuberculoma. This case illustrates the risk of misdiagnosis with this assay and the importance of histological confirmation of a pathological lesion prior to implementation of therapy.

$\mathrm{T}$ here has been a dramatic increase in the incidence of primary central nervous system lymphoma (PCNSL) in the setting of acquired immune deficiency syndrome (AIDS). ${ }^{1}$ This entity is defined as lymphoma limited to the brain and spinal cord without systemic disease. As with other AIDS related lymphomas, these are also aggressive B cell neoplasms, either diffuse large cell or diffuse immunoblastic non-Hodgkin's lymphoma. However, unlike AIDS related systemic lymphomas where only $30-50 \%$ of tumors are associated with Epstein-Barr virus (EBV) infection, AIDS related PCNSL have a $100 \%$ association with EBV. ${ }^{2}$

Accurate and timely diagnosis of AIDS related PCNSL has been challenging since its clinical presentation resembles that of toxoplasmosis and other opportunistic infections. ${ }^{3}$ The definitive diagnosis of this condition can only be made with a CNS biopsy. ${ }^{4}$ However, this poses many risks to the patients and surgical teams. As a result, it has become a common practice in many medical centres to presumptively diagnose patients with PCNSL if they fail to respond to antitoxoplasmosis regimens. ${ }^{5}$ More recently, the detection of EBV DNA in cerebrospinal fluid (CSF) samples of nearly all patients with PCNSL has established this assay as a diagnostic test for this condition..$^{6-9}$

Here we present a case of biopsy proven intramedullary tuberculoma in a patient with AIDS previously diagnosed as having intramedullary PCNSL after EBV DNA was detected in his CSF. He was presumptively diagnosed with PCNSL and underwent a course of radiation therapy. After a lack of response, he underwent an open biopsy of this cord lesion for definitive diagnosis.

\section{CASE REPORT}

This 50 year old man initially presented with inguinal lymphadenopathy and back and left sided leg pain in July
2001. Approximately one month later he developed lower extremity weakness which manifested in a fall down the stairs. He had no evidence of bowel or bladder dysfunction at that time. A magnetic resonance imaging (MRI) scan of his entire spine revealed a T2 bright intramedullary lesion at T9/ T10 levels with cord expansion. The lesion brightly enhanced after administration of contrast (fig 1A, B). A work-up revealed positive HIV serology with a viral load of 750000 copies $/ \mathrm{ml}$ and a CD4 count of $43 / \mu \mathrm{l}$. He was started on a regimen of stavudine (d4T), lamivudine (3TC), and efavirenz, for management of AIDS as well as pyrimethamine and sulfadiazine for a presumptive diagnosis of intramedullary toxoplasmosis.

After a two week period, the patient began to have episodic urinary incontinence with further progression of lower extremity weakness to the point of inability to ambulate. A lumbar puncture at that time showed slightly increased protein $(67 \mathrm{mg} / \mathrm{dl}$; reference range $15-45 \mathrm{mg} / \mathrm{dl})$, normal glucose and 22 cells/ $\mu \mathrm{l}$ (98\% lymphocytes). Polymerase chain reaction (PCR) analysis of CSF showed presence of EBV DNA with a viral titre of 660 copies $/ \mathrm{ml}$. The patient was diagnosed as having primary CNS lymphoma and was started on a regimen of radiation therapy. He underwent seven sessions of 180 cGy of external beam therapy with two additional boosts of 2200 cGy. His lower extremity strength continued to deteriorate and he was unable to stand a few weeks after conclusion of radiation therapy. Repeat imaging showed the persistence of the intramedullary lesion. Surveillance MRI of the entire neuraxis did not reveal additional lesions at this time.

The patient underwent an open biopsy of this lesion in the thoracic spinal cord. Postoperative MRI confirmed proper sampling of the lesion (fig $\mathrm{IC}$ ). Histological analysis showed non-caseating granulomas surrounded by reactive gliosis and increased scattered histiocytes. Acid fast bacilli (AFB) stain demonstrated presence of numerous AFB in multiple specimens (fig 2). Gomori methenamine silver (GMS) stain for fungi and Giemsa stain for toxoplasma were negative. There was no evidence of lymphoproliferation. The patient was started on a four drug antituberculosis (TB) regimen. Further enquiry of his past medical history revealed a history of exposure to tuberculosis in the 1950s as a child, at which time his father and brother were hospitalised in a TB sanitarium.

Approximately three months after transfer to a skilled nursing facility, he presented with increased confusion and headaches, along with nausea and vomiting. An MRI of the entire neuraxis revealed new intraparenchymal lesions in the pons and cervicomedullary junction which were hypodense on $\mathrm{Tl}$ and hyperdense on $\mathrm{T} 2$ sequences. In addition,

Abbreviations: AFB, acid fast bacilli; AIDS, acquired immune deficiency syndrome; EBV, Epstein-Barr virus; MRI, magnetic resonance imaging; PCNSL, primary central nervous system lymphoma; PCR, polymerase chain reaction 

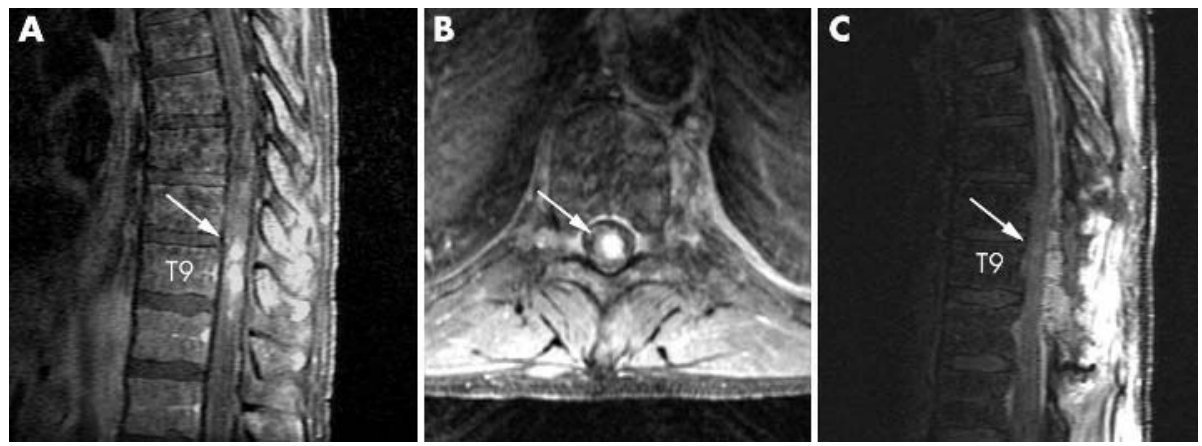

Figure 1 Contrast-enhanced (CE) MRI demonstrating the intramedullary lesion at T9. Note minimal cord expansion and the lack of meningeal enhancement. (A) Preoperative sagittal CE T1 images demonstrating the lesion in the substance of the spinal cord (arrow). (B) Preoperative axial CE T1 images demonstrating the involvement of the central portion of the cord. (C) Postoperative sagittal CE Tl images demonstrating the proper biopsy sampling of the lesion.

increased T2 signal was identified diffusely in the subependymal region throughout the cerebral hemispheres. CSF studies revealed $360 \mathrm{WBC} / \mathrm{HPF}$ with $80 \%$ lymphocytes, protein $2072 \mathrm{mg} / \mathrm{dl}$, and low glucose. As these findings were suggestive of disseminated TB cerebritis/meningitis he was continued on anti-TB therapy. He continued to deteriorate neurologically and died two weeks later of complications from a bout of pneumonia.

\section{DISCUSSION}

Prior to the advent of CSF-EBV PCR assay, the difficulty in diagnosis of intrinsic spinal cord lesions in the setting of AIDS had led to the adoption of a practical approach to the management of these patients. This approach included treating a CNS mass lesion in an AIDS patient as though it were toxoplasmosis first, and then if the patient did not respond to antitoxoplasmosis regimens, as a lymphoma, which often included radiation treatment. ${ }^{10}{ }^{11}$ A biopsy of the lesion can eliminate some of the uncertainty associated with this approach. However, CNS biopsy is invasive and in 5-33\% of cases no diagnosis can be reached due to sampling problems or tissue non-viability. ${ }^{12} 13$

Recently, detection of CSF-EBV DNA by PCR in AIDS patients has been reliably associated with primary CNS lymphoma. The basis for this approach is the observation that nearly all AIDS associated primary CNS lymphomas occur in the setting of EBV infection. ${ }^{2}$ EBV DNA has been detected in the CNS of nearly all patients with CNS lymphoma and almost never ( $1 / 86$ patients) in the CNS of patients without it. Multiple studies have reported the utility of a PCR assay for detection of EBV DNA in the CSF of AIDS patients with PCNSL. ${ }^{67914}$ The specificity and sensitivity reported from these studies are generally $90-100 \%$ with positive and negative predictive values reaching near $100 \%$. Cingolani et al reported that a positive PCR was not only predictive of CNS involvement, but it also preceded identification of lymphomatous lesions on MRI by a mean of 35 days. ${ }^{9}$ al-Shahi et al have reported detection of EBV DNA in CSF samples as early as 17 months prior to imaging abnormalities. ${ }^{8}$ These observations have led to the acceptance of this assay as an important tool for diagnosis of PCNSL.

Although PCNSL and toxoplasmosis are the most common space occupying lesions in the CNS in patients with AIDS, TB which can also present with mass effect should be included in this differential diagnosis. The incidence of pulmonary TB is almost 500 times greater in AIDS patients compared with the general population. ${ }^{15}$ Furthermore, the incidence of CNS TB is dramatically increased in AIDS patients. ${ }^{16}$ Although meningitis is the most common presentation of $\mathrm{TB}$ in the CNS, it can take a variety of forms including cerebritis, abscess, or tuberculoma. ${ }^{17}$ Intramedullary tuberculomas, although rare, usually present with myelopathy which can be rapidly progressive, much like the symptoms described in this case. ${ }^{18-20}$

Clinical symptomatology and presentation of intramedullary tuberculomas can be virtually indistinguishable from PCNSL and toxoplasmosis. ${ }^{21}$ These patients present with a subacute paraparesis that progresses over one or two months. ${ }^{22}$ In most patients evaluation of CSF reveals an active inflammatory response with pleocytosis, hypoglycorrhachia and a very high protein level..$^{15} 23$ The MRI features of CNS tuberculomas include an isointense appearance of the grey matter on Tl-weighted images and may have a slightly hyperintense rim. On T2-weighted images the appearance can vary depending on the pathological state of the tuberculoma, ranging from isointense to hypointense. ${ }^{24} 25$

TB, PCNSL, and toxoplasmosis can have very similar clinical and radiological characteristics especially in the
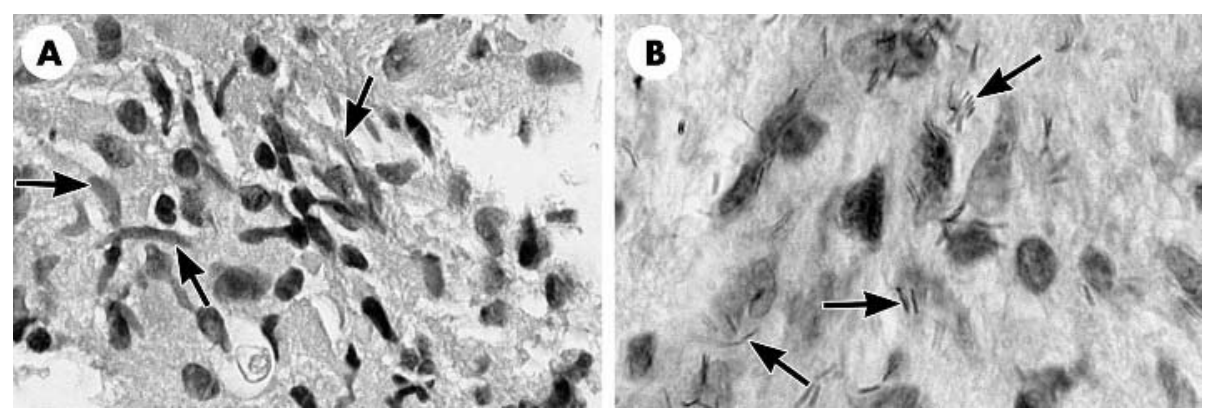

Figure 2 Histological demonstration of the intramedullary tuberculoma and acid fast bacilli. (A) H\&E section of the biopsied specimen shows a granuloma with epithelioid histiocytes (arrows) $(\times 40)$. (B) Acid-fast bacilli (arrows) in the biopsied specimen $(\times 100)$. 
setting of AIDS where atypical features of the pathologies may be present. The advantages of a non-invasive method for differentiating among these are clear. The CSF-EBV PCR assay is highly sensitive and specific for AIDS related PCNSL and has quickly become an alternative to biopsy and histological diagnosis. Although this approach may circumvent risks associated with biopsy and can result in early therapy, we believe that the AIDS clinician should be aware of the risk of misdiagnosis, as demonstrated by this case.

\section{Authors' affiliations}

A A Mohit, R Rostomily, Department of Neurological Surgery, University of Washington School of Medicine, Seattle, WA, USA

P Santiago, Department of Neurological Surgery, Washington

University School of Medicine, St Lovis, MO, USA

Competing interests: none declared

Correspondence to: A A Mohit, Department of Neurological Surgery, University of Washington School of Medicine, Seattle, WA, USA; abmohit@u.washington.edu

Received 10 October 2003

In revised form 18 January 2004

Accepted 20 January 2004

\section{REFERENCES}

1 Ziegler JL, Beckstead JA, Volberding PA, et al. Non-Hodgkin's lymphoma in 90 homosexual men. Relation to generalized lymphadenopathy and the acquired immunodeficiency syndrome. N EnglJ Med 1984;311:565-70.

2 MacMahon EM, Glass JD, Hayward SD, et al. Epstein-Barr virus in AIDSrelated primary central nervous system lymphoma. Lancet 1991;338:969-73.

3 Ciricillo SF, Rosenblum ML. Use of CT and MR imaging to distinguish intracranial lesions and to define the need for biopsy in AIDS patients. J Neurosurg 1990;73:720-4.

4 lacoangeli $M$, Roselli $R$, Antinori $A$, et al. Experience with brain biopsy in acquired immune deficiency syndrome-related focal lesions of the central nervous system. Br J Surg 1994;81:1508-11.

5 Mathews C, Barba D, Fullerton SC. Early biopsy versus empiric treatment with delayed biopsy of non-responders in suspected HIV-associated cerebral toxoplasmosis: a decision analysis. AIDS 1995;9:1243-50.

6 Arribas JR, Clifford DB, Fichtenbaum CJ, et al. Detection of Epstein-Barr virus DNA in cerebrospinal fluid for diagnosis of AIDS-related central nervous system lymphoma. J Clin Microbiol 1995;33:1580-3.
7 Plebani A, Pinzani R, Vago L, et al. Epstein-Barr virus DNA in the cerebrospinal fluid of an HIV patient with primary cerebral lymphoma. Eur J Pediatr 1998;157:291-3.

8 al-Shahi R, Bower M, Nelson MR, et al. Cerebrospinal fluid Epstein-Barr virus detection preceding HIV-associated primary central nervous system lymphoma by 17 months. J Neurol 2000;247:471-2.

9 Cingolani A, Gastaldi R, Fassone L, et al. Epstein-Barr virus infection is predictive of CNS involvement in systemic AIDS-related non-Hodgkin's lymphomas. J Clin Oncol 2000;18:3325-30.

10 Donahue BR, Sullivan JW, Cooper JS. Additional experience with empiric radiotherapy for presumed human immunodeficiency virus-associated primary central nervous system lymphoma. Cancer 1995:76:328-32.

11 Yarchoan R, Jaffe ES, Little R. Diagnosing central nervous system lymphoma in the setting of AIDS: a step forward. J Natl Cancer Inst 1998;90:346-7.

12 Chappell ET, Guthrie BL, Orenstein J. The role of stereotactic biopsy in the management of HIV-related focal brain lesions. Neurosurgery 1992:30:825-9.

13 Karahalios D, Breit R, Dal Canto MC, et al. Progressive multifocal leukoencephalopathy in patients with HIV infection: lack of impact of early diagnosis by stereotactic brain biopsy. J Acquir Immune Defic Syndr 1992;5:1030-8.

14 Brink NS, Sharvell Y, Howard MR, et al. Detection of Epstein-Barr virus and Kaposi's sarcoma-associated herpesvirus DNA in CSF from persons infected with HIV who had neurological disease. I Neurol Neurosurg Psychiatry 1998;65:191-5.

15 Berenguer J, Moreno S, Laguna F, et al. Tuberculous meningitis in patients infected with the human immunodeficiency virus. N Engl J Med 1992;326:668-72.

16 Sathe SS, Reichman LB. Mycobacterial disease in patients infected with the human immunodeficiency virus. Clin Chest Med 1989;10:445-63.

17 Whiteman ML. Neuroimaging of central nervous system tuberculosis in HIVinfected patients. Neuroimaging Clin North Am 1997:7:199-214.

18 Bansal D, Singhi PD, Ray M, et al. Cervical intramedullary tuberculoma: acute presentation and rapid response to medical therapy. J Trop Pediatr 2002;48:55-7.

19 Borges MA, Carmo MI, Sambo MR, et al. Intramedullary tuberculoma in a patient with human immunodeficiency virus infection and disseminated multidrug-resistant tuberculosis: case report. Int J Infect Dis 1998;2:164-7.

20 Dastur HM, Shah MD. Intramedullary tuberculoma of the spinal cord. Indian Pediatr 1968:5:468-71.

21 Quencer RM, Post MJ. Spinal cord lesions in patients with AIDS Neuroimaging Clin North Am 1997;7:359-73.

22 Rhoton EL, Ballinger WE Jr, Quisling R, et al. Intramedullary spinal tuberculoma. Neurosurgery 1988:22:733-6.

23 Berger JR. Tuberculous meningitis. Curr Opin Neurol 1994;7:191-200.

24 Gupta RK, Gupta S, Kumar S, et al. MRI in intraspinal tuberculosis. Neuroradiology 1994;36:39-43.

25 Gupta VK, Sharma BS, Khosla VK. Intramedullary tuberculoma: report of two cases with MRI findings. Surg Neurol 1995;44:241-3; discussion 243-4. 